\section{Spondylurus magnacruzae (Greater Saint Croix Skink). Conservation.}

Date of observation: 19 June 1987. Location: U.S. Virgin Islands; Saint Croix, Green Cay. Coordinates: 17.7657, -64.6663. Elevation: $17 \mathrm{~m}$. Voucher: image. This is only known photograph of a living individual and only the third sighting of the species since 1882. One specimen was collected in 1964 on Green Cay (Hedges, B. \& Conn, C.E., 2012, A new skink fauna from Caribbean islands [Squamata, Mabuyidae, Mabuyinae], Zootaxa, 3288, 1-244.) and the other sighting was also made on Green Cay, in September 2000 (Evans MA, et al., 2010, Sandy Point, Green Cay and Buck Island National Wildlife Refuges. Conservation Action Plan. U.S. Department of the Interior, Fish and Wildlife Service, 264 p.). There is no record of a skink (any species) from the main island of Saint Croix since 1882 (Hedges \& Conn 2012). Green Cay (5.7 hectares) is a small islet only $450 \mathrm{~m}$ off the NE coast of Saint Croix. The sighting reported here (in 1987) was made in early afternoon (13:45 hrs) after a rain, in woodland habitat (primarily Cordia rickseckeri, with some C. alba) near the highest point on the island (southern end). The Saint Croix Ameiva (Ameiva polops) was found in the same habitat. Trees averaged $14 \mathrm{~cm}$ in diameter at breast height, with a density of 5-16 per $100 \mathrm{~m} 2$. Shrubs (Oplonia) comprised 5-35\% cover, and there was no grass cover. The soil was loose, easily dug by hand. The animal in the photo here possesses several typical characteristics of the species, including sharp, bold lateral stripes, reduced dorsolateral stripes, and a small ear opening, which distinguishes it from its closest relative Spondylurus spilonotus, occurring elsewhere in the Virgin Islands. The individual, a female, was $131 \mathrm{~mm}$ total length, $72 \mathrm{~mm}$ snout-vent length, and weighed 13 grams. It differs in many ways from the other species of skink on Saint Croix, Capitellum parvicruzae (Lesser Saint Croix Skink), which has a short head and greatly reduced hands, feet, and digits (Hedges \& Conn 2012). Capitellum parvicruzae has not been seen since the holotype and only specimen was collected in 1875 (Hedges \& Conn 2012). The introduction of the Small Indian Mongoose to Caribbean islands in the late nineteenth Century has been directly implicated in population reductions, extirpations, and extinctions of many species of reptiles, including 38 species of skinks (Hedges \& Conn 2012). Herpetologists have visited the main island of Saint Croix and its islets, including Green Cay, since the last sightings of skinks (both species) and no individuals have been seen. However, these two species were not recognized taxonomically until 2012, and therefore concerted and thorough searches are needed before they should be considered extinct.

S. Blair Hedges, Pennsylvania State University, Department of Biology, 208 Mueller Lab, University Park, Pennsylvania, 16802, USA, sbh1@psu.edu and Albert J. Meier, Western Kentucky University, Department of Biology, Bowling Green, Kentucky, 42101, USA, albert.meier@wku.edu.

Citation: Hedges SB, Meier AJ. 2013. Spondylurus magnacruzae (Greater Saint Croix Skink). Conservation. Caribbean Herpetology 46:1.

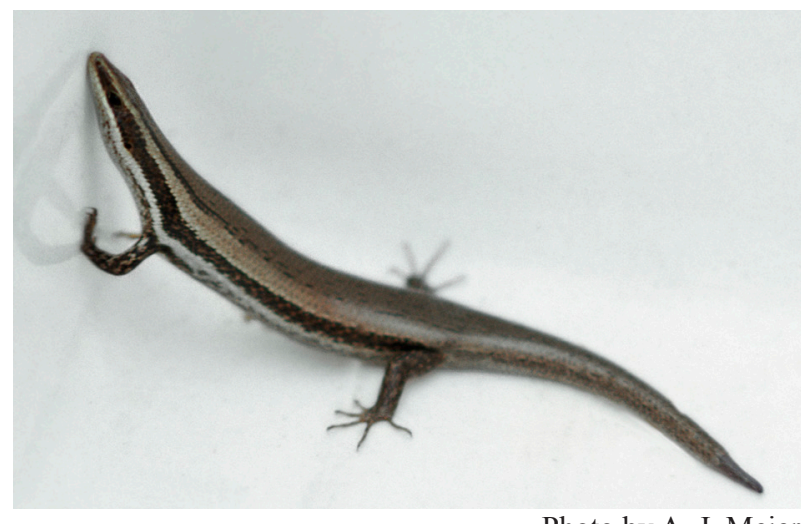

Photo by A. J. Meier 